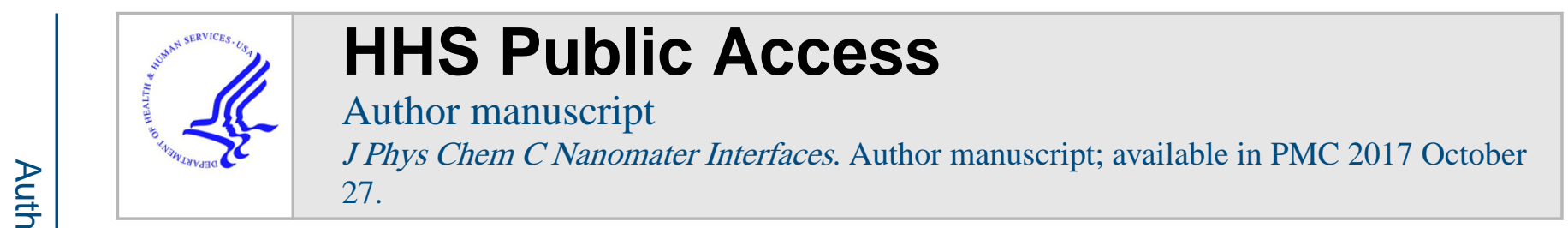

Published in final edited form as:

J Phys Chem C Nanomater Interfaces. 2016 October 27; 120(42): 24231-24239. doi:10.1021/acs.jpcc. $6 \mathrm{~b} 08469$.

\title{
Electrostatic Interactions and Protein Competition Reveal a Dynamic Surface in Gold Nanoparticle-Protein Adsorption
}

\author{
Ailin Wang, Y. Randika Perera, Mackenzie B. Davidson, and Nicholas C. Fitzkee* \\ Department of Chemistry, Mississippi State University, Mississippi State, Mississippi 39762, \\ United States
}

\section{Abstract}

Gold nanoparticle- (AuNP-) protein conjugates are potentially useful in a broad array of diagnostic and therapeutic applications, but the physical basis of the simultaneous adsorption of multiple proteins onto AuNP surfaces remains poorly understood. Here, we investigate the contribution of electrostatic interactions to protein-AuNP binding by studying the $\mathrm{pH}$-dependent binding behavior of two proteins, GB3 and ubiquitin. For both proteins, binding to 15 -nm citratecoated AuNPs closely tracks with the predicted net charge using standard $\mathrm{p} K_{\mathrm{a}}$ values, and a dramatic reduction in binding is observed when lysine residues are chemically methylated. This suggests that clusters of basic residues are involved in binding, and using this hypothesis, we model the $\mathrm{p} K_{\mathrm{a}}$ shifts induced by AuNP binding. Then, we employ a novel NMR-based approach to monitor the binding competition between GB3 and ubiquitin in situ at different $\mathrm{pH}$ values. In light of our model, the NMR measurements reveal that the net charge, binding association constant, and size of each protein play distinct roles at different stages of protein adsorption. When citrate-coated AuNPs and proteins first interact, net charge appears to dominate. However, as citrate molecules are displaced by protein, the surface chemistry changes, and the energetics of binding becomes far more complex. In this case, we observed that GB3 is able to displace ubiquitin at intermediate time scales, even though it has a lower net charge. The thermodynamic model for binding developed here could be the first step toward predicting the binding behavior in biological fluids, such as blood plasma.

\section{Graphical abstract}

\footnotetext{
*Corresponding Author. nfitzkee@ chemistry.msstate.edu. Phone: 662-325-1288. ASSOCIATED CONTENT

Supporting Information

The Supporting Information is available free of charge on the ACS Publications website at DOI: 10.1021/acs.jpcc.6b08469.

Derivation of the relationship between apparent adsorption capacity and $\mathrm{pH}$, numerical values for binding of GB3 lysine variants, HSQC spectra of GB3 and ubiquitin at varying $\mathrm{pH}$ values, documentation supporting the complete methylation of GB3, and a TEM image of the nanoparticles used in this study (PDF)
}

The authors declare no competing financial interest. 

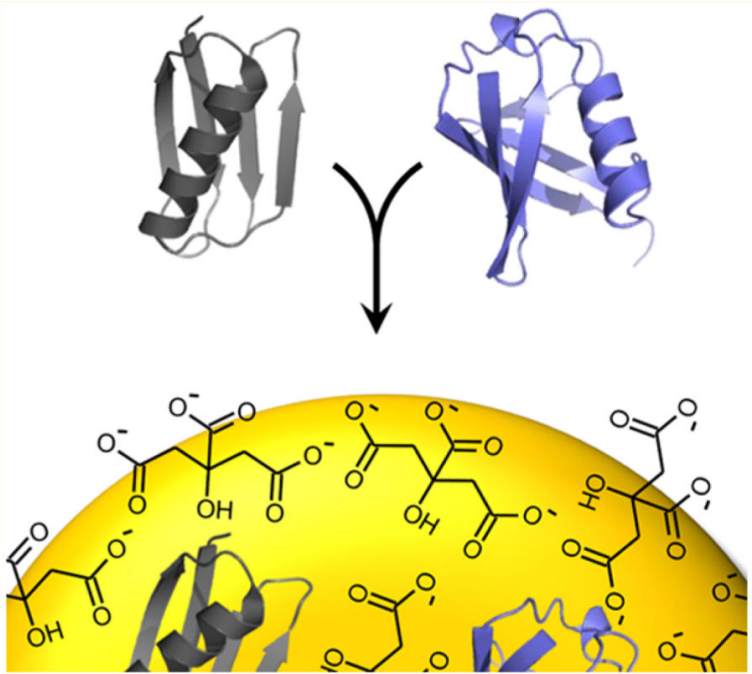

\section{INTRODUCTION}

Upon exposure to a solution containing gold nanoparticles (AuNPs), proteins spontaneously adsorb to the nanoparticle surface, leading to the formation of a stable surface coating, or biocorona. ${ }^{1-4}$ However, recent studies have demonstrated that the composition of the biocorona is not fixed in biological fluids and can vary over time depending on the tissue, protein concentration, binding affinity, and other physical factors, including size and charge. ${ }^{5-8}$ This complexity is important, because in addition to nanoparticle size, ${ }^{9}$ the surface chemistry of protein-coated AuNPs plays a critical role in cellular uptake and physiological response. ${ }^{10-12}$ Protein-functionalized AuNPs have been proposed as potential drug-delivery vectors, ${ }^{13-16}$ but functionalized AuNPs must be resilient to competition from other proteins as well as environmental changes. Unfortunately, in many cases, it remains impossible to predict how changes to the bulk solution will affect protein-coated surfaces.

Early studies of competitive adsorption investigated the binding of proteins in blood plasma to glass surfaces. These studies identified what is now termed the "Vroman effect": 17 Smaller, more abundant proteins were observed to bind to glass surfaces first, followed by larger proteins, which were believed to have higher affinity. This general behavior has been observed in several other studies. For example, a previous study of competitive protein adsorption suggested that the residence time of an adsorbed protein on a polystyrene surface depends on its molecular weight, concentration, and surface affinity and that the order of protein adsorption follows the Vroman sequence. ${ }^{18}$ In another study, Choi et al. used the Vroman effect to develop a protein sensor for detecting the extent of protein displacement on bare-gold compared to hydrophilic surfaces. ${ }^{19}$ However, other studies appear to contradict the expected displacement behavior. In one of these, Cedervall et al. observed that small proteins, as opposed to larger ones, could ultimately dominate on NP surfaces. In their study, human serum albumin was ultimately displaced by the much smaller apolipoprotein A-I on acrylamide polymeric nanoparticles. ${ }^{20}$ Another study found that the final composition of proteins on the NP surface can actually change as the serum concentration itself is altered. ${ }^{21}$ From these studies, it is evident that the composition of the biocorona in multicomponent 
systems does not reflect the concentration of proteins and that, although the Vroman effect is a useful generalization, it does not universally apply. Ultimately, any predictive model of competitive binding to nanoparticles will depend on the complex interplay of interactions between specific proteins and the nanoparticle surface itself. ${ }^{22}$

Electrostatic interactions have been indicated as one of the potentially important physical forces involved in competitive binding. For example, Lundqvist et al. found that the surface charge of nanoparticles influences the composition of the protein corona formed from human plasma. ${ }^{23}$ Specifically, they observed that nanoparticles with a positive surface charge attract a different distribution of proteins than neutral or negatively charged nanoparticles. Similarly, Boulos et al. found that the kinetics of the adsorption of BSA onto positively charged AuNPs is significantly faster than that onto negatively charged or neutral ones. ${ }^{24}$ Another important study identified that introducing different surface charges on AuNPs can influence the orientation of adsorbed a-synuclein. ${ }^{25}$ Electrostatic interactions are ultimately dependent on the $\mathrm{pH}$ of the surrounding environment, and this implies that all of the effects described above will be $\mathrm{pH}$-dependent. These effects might be particularly important in nanoparticle-based cancer therapeutics, given that the $\mathrm{pH}$ gradient across the cell membrane in tumors could be as much as one $\mathrm{pH}$ unit. ${ }^{26}$ The relationship between electrostatics, protein binding, and competition is an important one, but many unanswered questions remain about the thermodynamic and kinetic determinants of binding as they relate to charge-charge interactions.

Here, we investigate how electrostatic attraction can influence both affinity and competition in protein-AuNP adsorption. For two proteins, GB3 and ubiquitin, the binding behavior is strongly $\mathrm{pH}$-dependent, suggesting that the protein adsorption is mainly driven by electrostatic interactions. Although these proteins are not representative of those found in blood plasma and other bodily fluids, both GB3 and ubiquitin are well characterized and serve as useful platforms for understanding the biophysics of protein-nanoparticle interactions. For both proteins, a thermodynamic model is used to determine a referencestate (pH-independent) association constant, and the model is consistent with small to moderate $\mathrm{p} K_{\mathrm{a}}$ shifts $(<1.6)$ upon binding. Using the model, we predict the results of competitive binding as a function of $\mathrm{pH}$, and we design a novel NMR-based approach to measure competition in situ. We find that competition favors the protein with the higher net charge; however, the time-dependent composition of the protein corona changes with $\mathrm{pH}$, suggesting that, although electrostatic interactions remain important, a physical model for adsorption must also account for the changing nature of the surface itself.

\section{MATERIALS AND METHODS}

\section{Synthesis of Citrate-Stabilized AuNPs}

Gold(III) chloride trihydrate and sodium citrate dihydrate were purchased from SigmaAldrich. The 15-nm AuNPs were synthesized by the citric acid reduction method. ${ }^{27}$ After $100 \mathrm{~mL}$ of $1 \mathrm{mM} \mathrm{HAuCl}_{4}$ had been heated to boiling, $10 \mathrm{~mL}$ of $38.8 \mathrm{mM}$ sodium citrate solution was immediately mixed with the gold solution. The mixture was kept boiling for 20 min. After being allowed to cool, the AuNP solution was centrifuged at $9000 \mathrm{~g}$ for $45 \mathrm{~min}$. The concentrated AuNP solution was sonicated for 6 min at power level 1 on a Branson 
sonicator. Nanoparticles were assessed by UV-visible spectroscopy and transmission electron microscopy. ${ }^{28,29}$ The absorbance maximum was observed to be at $520 \mathrm{~nm}$, as predicted for this size ${ }^{29}$ and the average nanoparticle diameter was observed to be 13.7 $\pm 1.8 \mathrm{~nm}$ (Figure $\mathrm{S} 2$ ).

\section{Protein Preparation and Methylation}

All ubiquitin and GB3 protein variants were expressed and purified according to methods described previously. ${ }^{30}$ Isotopic labeling was modulated by the selective addition of ${ }^{15} \mathrm{~N}$ ammonium chloride or ${ }^{13} \mathrm{C}$-glucose to the $\mathrm{M} 9$ growth media. GB3 lysine variants were generated using site-directed mutagenesis (Agilent) and confirmed using DNA sequencing and mass spectrometry.

Methylation of GB3 protein was performed by reductive alkylation. ${ }^{31}$ Starting with $0.5 \mathrm{mM}$ GB3 in water at $\mathrm{pH} 7.0,4.0 \%(\mathrm{v} / \mathrm{v})$ formaldehyde was added to a final concentration of $0.16 \%$. After mixing by inversion, the protein solution was centrifuged at $16000 \mathrm{~g}$ for $2 \mathrm{~min}$. Sodium cyanoborohydrate was added as a reducing agent to a final concentration of $25 \mathrm{mM}$. The reaction mixture was incubated at room temperature, and the reaction was quenched after $1 \mathrm{~h}$ by adding ammonia (final concentration of $0.08 \%$ by volume). The reaction mixture was dialyzed against water, and complete methylation was confirmed by mass spectrometry.

\section{NMR Measurement of pH-Dependent Adsorption and Competition}

Solutions of protein $(20 \mu \mathrm{M})$ were prepared in $20 \mathrm{mM}$ phosphate buffer at $\mathrm{pH} 5.5,6.6,7.5$, and 8.3 and in $20 \mathrm{mM}$ ammonium acetate buffer at $\mathrm{pH}$ 4.6. After the addition of $6 \% \mathrm{D}_{2} \mathrm{O}$ and $200 \mu \mathrm{M} 4$ 4,4-dimethyl-4-silapentane-1-sulfonic acid (DSS), each protein sample was mixed with 20, 40, and $60 \mathrm{nM}$ AuNP solution and incubated overnight $(18 \mathrm{~h}) .{ }^{15} \mathrm{~N}$ heteronuclear single-quantum coherence (HSQC) NMR spectra were collected on a 600 $\mathrm{MHz}$ Bruker Avance III cryoprobe-equipped instrument as described previously. ${ }^{30}$ Briefly, the signal decrease in the presence of AuNPs is quantifiably related to the amount of adsorbed protein. Error bars were determined as the standard error of the mean for three independent measurements of protein adsorption.

For competition experiments, ${ }^{13} \mathrm{C}$-labeled wild-type (WT) GB3 and ${ }^{15} \mathrm{~N}$-labeled ubiquitin were mixed in $20 \mathrm{mM}$ phosphate buffer at $\mathrm{pH} 5.6$ and 7.9. After the addition of $6 \% \mathrm{D}_{2} \mathrm{O}$ and $200 \mu \mathrm{M}$ DSS, the protein solutions were mixed with AuNPs. The final concentrations of GB3, ubiquitin, and AuNPs were $25 \mu \mathrm{M}, 25 \mu \mathrm{M}$, and $80 \mathrm{nM}$, respectively. NMR spectra were recorded at intervals of $0.5,2$, and $18 \mathrm{~h}$. Signal filtering of ${ }^{15} \mathrm{~N}$ - and ${ }^{13} \mathrm{C}$-attached protons was performed using a half-filter experiment, ${ }^{32}$ with a WATERGATE element for water suppression. ${ }^{33,34}$ For each data point, three separate spectra were collected: one each for no filtering, ${ }^{13} \mathrm{C}$ filtering, and ${ }^{15} \mathrm{~N}$ filtering. Relative concentrations were measured relative to the DSS signal, recorded in a spectrum with no filtering. 


\section{RESULTS AND DISCUSSION}

\section{Evidence for Electrostatically Driven Binding}

Previously, we reported an NMR-based technique for measuring the maximum apparent adsorption capacity of AuNPs. ${ }^{30}$ In that work, we found that the native protein radius of gyration $\left(R_{\mathrm{g}}\right)$ accurately predicted the adsorption capacity for a data set of six proteins, including GB3 and ubiquitin, which were foud to have adsorption capacities of $200 \pm 5$ and $156 \pm 12$ proteins per 15-nm AuNP, respectively. Because GB3 (56 residues, 10.6- $\AA R_{\mathrm{g}}$ ) is smaller than ubiquitin (76 residues, $12.0-\AA R_{\mathrm{g}}$ ), more GB3 can bind to the surface of the AuNP.

Here, we observed that the apparent binding capacities of the AuNPs for these two proteins are both $\mathrm{pH}$-dependent. Our original work was performed at low $\mathrm{pH}(\sim 5)$, but as the $\mathrm{pH}$ was increased and the net charge went from positive to neutral, the apparent binding capacity also decreased. Both GB3 and ubiquitin exhibit a decrease in adsorption capacity to approximately 125 proteins per AuNP at $\mathrm{pH} 8.3$ (Figure 1A). This is reasonable, given that our AuNPs are coated in citrate and have a negative net charge after synthesis. ${ }^{35}$ To our knowledge, however, such an effect has not been previously reported. Protein structure is sensitive to $\mathrm{pH}$ and can unfold under acidic conditions, ${ }^{36}$ but neither GB3 nor ubiquitin demonstrated substantial changes as a function of $\mathrm{pH}$, as monitored by ${ }^{15} \mathrm{~N}$ HSQC spectra (Figures S3 and S4). This suggests that the observed changes originate from protein charge and not a conformational change. The isoelectric points (pI) of GB3 and ubiquitin, predicted from model $\mathrm{p} K_{\mathrm{a}}$ values, are 4.8 and 6.8 , respectively. At or above the $\mathrm{pI}$, the protein adopts a neutral or negative net charge, which would repel the net charge of the citrate-coated AuNP. From this observation, we hypothesized that binding is primarily driven by electrostatic interactions.

To confirm this hypothesis, we disrupted the electrostatic interactions by reductively methylating all lysine residues on GB3. ${ }^{31,38}$ Chemical methylation retains the positive charge of lysine residues but sterically disrupts electrostatic interactions through the addition of two methyl groups. GB3 has seven Lys amine groups that can be methylated, in addition to its $\mathrm{N}$-terminus. Complete methylation was confirmed by liquid chromatography-mass spectrometry (LCMS) (Figure S5), and ${ }^{15} \mathrm{~N}$ HSQC demonstrated that the GB3 structure was unperturbed (Figure S6). Surprisingly, at $\mathrm{pH} 7$, methylation reduced the apparent binding capacity of GB3 by more than $70 \%$, from $127 \pm 15$ to $35 \pm 4$ proteins per AuNP (Figure 1B). This impaired binding supports our hypothesis that protein charge substantially influences the physical mechanism of AuNP adsorption. We initially attempted to monitor adsorption capacity as a function of salt concentration. The increased ionic strength from high salts reduces the strength of electrostatic interactions. ${ }^{39,40}$ However, the concentrated AuNPs used in our studies tended to aggregate at the high salt concentrations typically used in such studies. ${ }^{41}$

\section{An Electrostatically Driven Thermodynamic Model for Binding}

To explore the energetics of AuNP-protein interactions, we developed a thermodynamic model for binding. Close examination of the electrostatic surfaces ${ }^{42}$ of GB3 and ubiquitin 
reveals localized clusters of basic residues (Figure 2). Our model assumes that, after initial protein-AuNP association, these clusters of residues determine the surface interaction energy. This hypothesis is supported by our results in the preceding section, as well as recent work identifying an interaction between the basic $\mathrm{N}$-terminus of a-synuclein and citratecoated AuNPs. ${ }^{25}$ Moreover, the ubiquitin surface is similar to what was identified in earlier studies of ubiquitin-surface interactions. ${ }^{43-46}$ Each cluster of ionizable residues experiences different $\mathrm{p} K_{\mathrm{a}}$ values depending on whether the protein is adsorbed on the AuNP surface or exposed to solution (Figure 3A). For simplicity, model-compound $\mathrm{p} K_{\mathrm{a}}$ values are used for the solution state, and each residue type is assigned an identical $\mathrm{p} K_{\mathrm{a}}$ shift. Specifically, all aspartic acid residues in the binding cluster are assumed to experience an identical $\mathrm{p} K_{\mathrm{a}}$ shift, from the model-compound $\mathrm{p} K_{\mathrm{a}, \mathrm{Asp}}^{\mathrm{f}}$ to the adsorbed value of $\mathrm{p} K_{\mathrm{a}, \mathrm{Asp}}^{\mathrm{b}}$, where $\mathrm{b}$ and $\mathrm{f}$ correspond to bound (adsorbed) and free states, respectively. Because Asp has a negative charge at neutral $\mathrm{pH}$, when it interacts unfavorably with the citrate on the AuNP surface, its $\mathrm{p} K_{\mathrm{a}, \mathrm{Asp}}^{\mathrm{b}}$ should shift up relative to the model-compound value. We assume that lysine residues, which are effectively fully deprotonated in our experiments, as well as residues not involved in binding, do not experience $\mathrm{p} K_{\mathrm{a}}$ shifts. Therefore, our reference state is a state in which all Asp and Glu residues at the binding site are deprotonated (negatively charged) and all other ionizable residues are protonated. This reference state corresponds to the expected ionization state of the protein in solution at $\mathrm{pH}$ 7. The reference state has an intrinsic, $\mathrm{pH}-$ independent binding affinity of $K_{\mathrm{in}}$, and it is possible to predict the apparent association constant at any $\mathrm{pH}\left(K_{\text {app }}\right)$ given $K_{\text {in }}$, the number of Asp and Glu residues at the binding site $\left(N_{\mathrm{r}}\right)$, and the corresponding $\mathrm{p} K_{\mathrm{a}}$ shifts. The $\mathrm{pH}$-dependent binding affinity $K_{\text {app }}$ can then be related to the apparent binding capacity, measured by NMR spectroscopy as the slope of the detected binding capacities(e.g., Figure 1C). A complete mathematical derivation of the model is included in the Supporting Information (SI).

Our previous study ${ }^{37}$ suggested that GB3 and ubiquitin remain globular on AuNP surfaces, and another work indicated that some enzymes can retain their function when adsorbed on nanoparticles. ${ }^{49}$ Therefore, we did not consider structural rearrangement in our model. GB3 and ubiquitin share similar shapes, with a single $\alpha$-helix packed against a $\beta$-sheet. ${ }^{47,48}$ The interaction surfaces for both proteins are predicted to lie on the exposed face of each $\beta$-sheet, where several Lys and Arg residues cluster into a basic surface (Figure 2A,B). For GB3, this patch includes three core Lys residues (K4, K13, and K50) flanked by three acidic residues (E15, D46, and D47). For ubiquitin, the patch is larger and includes three Lys residues (K6, K48, and K63), three Arg residues (R42, R72, and R74), and a His residue (H68), in addition to two acidic residues (D39 and E64).

\section{Confirmation of the GB3 Binding Site by Mutagenesis}

Although the interaction surface identified by electrostatics calculations for ubiquitin is consistent with those found in previous studies, ${ }^{44,46}$ to our knowledge, no prior work has investigated the interacting surface of GB3. To test the location of the GB3 binding site, we generated a series of single-site variants, systematically replacing all lysine residues with alanine. Then, we measured the AuNP binding capacity as before for these seven variants. As expected on the basis of our hypothesis, the residues in the binding region identified by 
the electrostatic surface calculations were the most disruptive to the AuNP-GB3 interaction (Figure 2C, Table S1). Whereas WT GB3 has a surface coverage of 200 protein molecules per 15-nm AuNP, changing K4, K13, and K50 to Ala reduced binding to levels of 150 molecules per AuNP on average ( $p \leq 0.001$ for all three variants). These data strongly suggest that these three residues comprise the binding site and that electrostatic interactions at this site drive the initial association between GB3 and citrate-coated AuNPs. This result also supports the predicted site identified by our electrostatic calculations, and it is in general agreement with a previous experimental study that found that the basic $\mathrm{N}$-terminal residues of a-synuclein were preferentially attracted to the citrate-coated AuNP surface. ${ }^{25}$ With the binding site for GB3 confirmed, we proceeded to fit parameters in our thermodynamic model.

\section{Estimation of $p K_{\mathrm{a}}$ Shifts and Binding Affinities of AuNP-Bound GB3 and Ubiquitin}

At the high concentrations needed for NMR measurements (60 nM or higher), AuNPs tend to aggregate at extremes of $\mathrm{pH}$, either lower than 4.5 or higher than 9.0. This limits the $\mathrm{pH}$ range over which binding can be reliably measured and tested using our model. To reduce the number of parameters and simplify the model, we constrained the parameters according to simple physical principles. First, because all Asp and Glu residues experience roughly the same environment on the NP surface, all of these residues were assumed to have similar $\mathrm{p} K_{\mathrm{a}}^{\mathrm{b}}$ values in the AuNP-bound state. Second, because Lys and Arg already strongly favor an ionized state at the $\mathrm{pH}$ values used in our experiments, we assumed no $\mathrm{p} K_{\mathrm{a}}$ shifts upon binding for these residues. Fitting was insensitive to histidine $\mathrm{p} K_{\mathrm{a}}$ shifts in ubiquitin, and GB3 lacks His residues altogether, so histidines were not included. Finally, maximal binding capacities from our previous work were used without optimization. ${ }^{30}$ This leaves two parameters ( $K_{\mathrm{a}}^{\mathrm{b}}$ and $K_{\mathrm{in}}$ ) that could be fit reliably from our data (Table 1 and Figure 3B). After parameter optimization, the model accurately describes the observed experimental results over the measured $\mathrm{pH}$ range $\left(\mathrm{GB} 3, r^{2}=0.9999\right.$; ubiquitin, $\left.r^{2}=0.98\right)$ and produces physically realistic values for the parameters. The association constants fall in the same range as those observed using both radioisotope labeling ${ }^{50}$ and fluorescence measurements. ${ }^{51}$ Although it has been observed that the inner filter effect can complicate fluorescence measurements of AuNP adsorption, ${ }^{52}$ it seems clear that protein-AuNP adsorption reproducibly yields dissociation constants in the low micromolar range, regardless of the approach used.

An examination of the fit parameters reveals several trends for the two proteins. First, the Asp and Glu $\mathrm{p} K_{\mathrm{a}}$ values in both GB3 and ubiquitin appear to shift upward to values near 5.2 (Table 1). We believe that this represents the first quantitative estimates of $\mathrm{p} K_{\mathrm{a}}$ shifts for protein-nanoparticle binding. The observed values make physical sense, given the negatively charged surface of the citrate-coated AuNPs. Because the two proteins exhibit similar shifts, this suggests that all exposed acidic residues experience similar chemical environments on the AuNP surface. Second, the intrinsic reference-state $K_{\text {in }}$ value, corresponding to a fully deprotonated binding site, is approximately twice as favorable for ubiquitin as it is for GB3. As described above, $K_{\text {in }}$ refers to a state in which the acidic residues at the binding site are deprotonated and the rest of the protein is unperturbed. Ubiquitin has a higher net charge than GB3, and therefore, $K_{\text {in }}$ is expected to be correspondingly higher based on the chosen 
reference state. However, a third consequence is also evident: As $\mathrm{pH}$ is lowered and acidic residues are neutralized, GB3 binding is predicted to become more favorable with respect to that of ubiquitin. This is because of the number of acidic residues in each protein's binding site. As GB3's three residues become neutral at low $\mathrm{pH}$, the electrostatic repulsion diminishes to a greater extent than what is seen in ubiquitin's binding site, which has only two acidic residues. Thus, the apparent (pH-dependent) $K_{\text {app }}$ value is predicted to become more favorable for GB3 below approximately pH 5.3 (Figure 3C). This change is predicted even though ubiquitin always maintains a higher net charge than GB3 (Figure 3D).

\section{Binding Competition between Ubiquitin and GB3}

The parameters from our model predict that the AuNP-ubiquitin interaction will be favored over GB3 at pH 6-9. At lower $\mathrm{pH}$, the GB3 binding affinity is predicted to increase relative to that of ubiquitin for reasons described above. To test this prediction, we developed an NMR-based method to monitor competitive binding in situ as a function of time. Briefly, a 50:50 mixture of ${ }^{13} \mathrm{C}$-GB3 and ${ }^{15} \mathrm{~N}$-ubiquitin was prepared, and adsorption for each protein was quantified independently and nondisruptively using an NMR half-filter experiment (Figure 4A). ${ }^{32}$ When AuNPs were added to a mixture of ubiquitin and GB3, it was observed that neither GB3 nor ubiquitin reached their maximal binding potentials; instead, competition occurred. For the 50:50 mixture of GB3 and ubiquitin used here, if the two proteins interacted identically with the AuNP surface, one would expect their AuNP adsorption behaviors to be similar, because they have approximately the same size. On the other hand, if one protein interacted more strongly with the surface, it should exhibit quantifiably larger binding. Here, we express binding as a fraction of the maximum possible protein bound at a given $\mathrm{pH}$ (Figure 4B,C). For example, at pH 5, a maximum of $200 \mathrm{~GB} 3$ molecules or 156 ubiquitin molecules can bind a 15-nm AuNP. By this definition, a binding fraction of 0.5 for each protein would imply that 100 molecules of GB3 were bound to the AuNP at this $\mathrm{pH}$, along with 78 molecules of ubiquitin. Because of the size difference between GB3 and ubiquitin, the fractions do not necessarily add up to 1 and instead strictly reflect the binding observed during competition relative to single-protein binding.

Several factors are thought to influence competitive binding: overall net charge, thermodynamic favorability ( $K_{\text {app }}$ ), binding kinetics, and protein size. Recent work demonstrated that AuNP adsorption is under kinetic control and that the order of addition of adsorbed compounds can affect a nanoparticle's corona. ${ }^{53}$ This observation is compatible with the extremely slow exchange kinetics observed for protein-AuNP conjugates. ${ }^{30,37}$ However, competition experiments such as the ones performed here can nevertheless probe binding energetics, as the more strongly interacting protein will be drawn to the AuNP surface in a mixture of two different proteins. As time progresses, the dynamic nature of the surface is revealed as adsorption is monitored over time (Figure 4B,C). Thus, these experiments have a distinct advantage over mass-spectrometry-based measurements, where quantitation of adsorption is complicated by the removal of proteins from the NP surface. ${ }^{7,54,55}$

At pH 7.9 (Figure 4B), ubiquitin was found to bind at approximately $40 \%$ of its maximum binding potential and to stay constant for the duration of the 18-h experiment. GB3, on the 
other hand, exhibited lower binding initially, but ultimately reached $40 \%$ of its maximal single-protein binding as well. No changes were observed beyond $18 \mathrm{~h}$. Although this behavior likely reflects the fact that ubiquitin interacts more favorably than GB3 at $\mathrm{pH} 7.9$, GB3 is clearly able to bind significantly at longer time scales once ubiquitin has already coated the AuNP surface. Prior work suggested that single-protein adsorption is nearly complete after $1 \mathrm{~h},{ }^{30,55}$ but here, competition appears to have slowed the binding kinetics considerably. This observation might result from the fact that ubiquitin partially occludes the AuNP surface, making it more difficult for GB3 to interact with the remaining negatively charged surface area of the AuNP. In addition, competition between GB3 and ubiquitin near the surface might disrupt the mobility of ubiquitin that has already bound, slowing the adsorption process further.

The situation was strikingly different at $\mathrm{pH} 5.6$ (Figure 4C). Here, ubiquitin was found to bind with even greater affinity initially, approaching $65 \%$ of the maximum observed for single-protein binding. Thus, it seemed that ubiquitin wanted to bind with greater affinity at lower $\mathrm{pH}$, possibly resulting from its larger overall net charge (Figure 3D). GB3 was found to bind less initially at low $\mathrm{pH}$, to a small but statistically significant amount. Although this is contrary to what our model predicts, it makes sense given the increased net charge of ubiquitin. However, at $2 \mathrm{~h}, \mathrm{~GB} 3$ binding appeared to displace ubiquitin, displacing it from the surface, whereas GB3 binding continued to increase. This is consistent with a model in which, at early times, ubiquitin is rapidly drawn to the AuNP surface on account of its high net charge. Then, as the distributions of proteins near the surface equilibrates, GB3 is able to gradually diminish ubiquitin binding from its initial levels because of the higher relative affinity of its binding surface. At the final time, GB3 binding is lower than 50\% of its maximum single-protein value, but the ubiquitin binding is down significantly from the initial measurement at $30 \mathrm{~min}$.

Combined, these data point to both strengths and weaknesses in our model, and they suggest a dynamically changing nature of the AuNP surface throughout the course of our experiments. When first exposed to nanoparticles, both proteins spontaneously approach the surface. Given that ubiquitin always outbinds GB3, this initial approach appears to be driven largely by electrostatic attraction, owing to ubiquitin's greater net charge. We hypothesize that this initial attraction is nonspecific and results in a higher density of ubiquitin near the AuNP surface (Figure 5A). After this initial nonspecific association, however, proteins begin to bind more specifically as a biocorona is formed. ${ }^{20}$ At this stage of adsorption, the binding surface identified by mutagenesis and electrostatics calculations is most relevant. At high $\mathrm{pH}$, ubiquitin is intrinsically more favorable than GB3, and therefore, ubiquitin, with its higher local concentration, adsorbs to the surface and cannot afterward be easily displaced. GB3 is also adsorbed, but to a lesser extent, binding to exposed surface without displacing ubiquitin (Figure 5B). At low pH, ubiquitin is also driven to the surface because of its high charge, but after this initial association, the higher affinity of the GB3 binding site allows GB3 to displace some of the bound ubiquitin as it adsorbs onto the AuNP surface (Figure 5C). This behavior occurs only at low $\mathrm{pH}$, when the acidic residues on the GB3 binding site are partially protonated and attraction to GB3 is therefore stronger. At long time scales, the situation becomes more complex; the AuNP, now stripped of most of its citrate, no longer behaves like a negatively charged sphere. Adsorption at these longer time scales is likely 
driven by a combination of van der Waals and protein-protein interactions on the AuNP surface. Thus, although our thermodynamic model and mutagenesis data are useful in explaining the displacement of ubiquitin by GB3 at low pH at early time scales, additional considerations are needed to describe competition in its entirety, and it becomes clear that competitive adsorption, even for a two-protein system, is a very complex process.

The complexity of adsorption revealed by our competition experiments, together with the $\mathrm{pH}$-dependent behavior of binding, suggest several important considerations for future studies of biocorona formation on AuNP surfaces. First, although studying single-protein adsorption can provide deep insight into protein-nanoparticle interactions, biological fluids are composed of complex protein mixtures, ${ }^{56}$ and the behaviors of protein mixtures cannot be easily inferred from the behaviors of their individual components. Studies such as these, as well as other studies monitoring competition, ${ }^{7}$ will be essential for understanding how protein mixtures influence adsorption as a function of time. These experiments are needed to drive new theoretical models for protein-protein and protein-surface interactions and could potentially lead to the development of better nanoparticle-based therapeutics. ${ }^{57}$ Second, it is likely that simulations of AuNP-protein interactions ${ }^{58}$ are not currently long enough to capture the complexity of both binding and competition. Tavanti et al. performed some of the first simulations of protein competition on a AuNP surface, ${ }^{58}$ and their course-grained approach was able to capture the behavior of multiple fibrinogen and insulin molecules as they competed for binding to a AuNP surface. Although their work represents the best attempt to date to model competitive binding, it is nevertheless limited to $100 \mathrm{~ns}$ of simulation time and cannot predict the $\mathrm{pH}$-dependent effects observed here. Finally, NMR spectroscopy is becoming an increasingly useful tool for characterizing protein-nanoparticle interactions. Although NMR spectroscopy has been used to characterize the interactions of individual proteins with surfaces in the past, ${ }^{25,46,59-64}$ to our knowledge, this work represents the first NMR-based study of multiple-protein binding to nanoparticle surfaces. We believe that the ability to measure competition conveniently and nondisruptively will prove exceedingly useful for investigating more complex systems in the future.

\section{CONCLUSIONS}

In summary, we have investigated the contribution of electrostatic interactions to proteinAuNP binding by studying two model proteins, GB3 and ubiquitin. We observd e a strong $\mathrm{pH}$ dependence of binding, and we found that binding is substantially reduced when lysine residues are methylated. Both of these results suggest that charge interactions dominate the adsorption of proteins on citrate-coated AuNPs. We have proposed a specific binding surface for GB3 and ubiquitin based on mutagenesis and electrostatic surface calculations, and using these structural data, we developed a thermodynamic model for predicting the outcome of competitive binding experiments. Although the model can explain the displacement of ubiquitin by GB3 at low $\mathrm{pH}$, other considerations are needed to explain how binding evolves over time. We propose that competitive binding is a complex process, influenced by the fact that the nanoparticle surface is constantly changing during the first hour after nanoparticles are exposed to protein mixtures. Although more work is needed, thermodynamic models such as the one presented here should prove to be a useful first step toward predicting adsorption in complex biological fluids such as blood plasma. 


\section{Supplementary Material}

Refer to Web version on PubMed Central for supplementary material.

\section{Acknowledgments}

We thank Dongmao Zhang for helpful discussion. This work was supported by the National Institute of General Medical Sciences of the National Institutes of Health under Award R15GM113152. The content is solely the responsibility of the authors and does not necessarily represent the official views of the National Institutes of Health.

\section{REFERENCES}

1. Walczyk D, Bombelli FB, Monopoli MP, Lynch I, Dawson KA. What the Cell "Sees" in Bionanoscience. J. Am. Chem. Soc. 2010; 132:5761-5768. [PubMed: 20356039]

2. Monopoli MP, Aberg C, Salvati A, Dawson KA. Biomolecular Coronas Provide the Biological Identity of Nanosized Materials. Nat. Nanotechnol. 2012; 7:779-786. [PubMed: 23212421]

3. Mahmoudi M, Lynch I, Ejtehadi MR, Monopoli MP, Bombelli FB, Laurent S. Protein-Nanoparticle Interactions: Opportunities and Challenges. Chem. Rev. 2011; 111:5610-5637. [PubMed: 21688848]

4. Tenzer S, Docter D, Kuharev J, Musyanovych A, Fetz V, Hecht R, Schlenk F, Fischer D, Kiouptsi K, Reinhardt C, et al. Rapid Formation of Plasma Protein Corona Critically Affects Nanoparticle Pathophysiology. Nat. Nanotechnol. 2013; 8:772-781. [PubMed: 24056901]

5. Shang W, Nuffer JH, Muñz-Papandrea VA, Colón W, Siegel RW, Dordick JS. Cytochrome c on Silica Nanoparticles: Influence of Nanoparticle Size on Protein Structure, Stability, and Activity. Small. 2009; 5:470-476. [PubMed: 19189325]

6. Casals E, Pfaller T, Duschl A, Oostingh GJ, Puntes V. Time Evolution of the Nanoparticle Protein Corona. ACS Nano. 2010; 4:3623-3632. [PubMed: 20553005]

7. Lundqvist M, Stigler J, Cedervall T, Berggård T, Flanagan MB, Lynch I, Elia G, Dawson K. The Evolution of the Protein Corona Around Nanoparticles: A Test Study. ACS Nano. 2011; 5:75037509. [PubMed: 21861491]

8. Walkey CD, Chan WCW. Understanding and Controlling the Interaction of Nanomaterials with Proteins in a Physiological Environment. Chem. Soc. Rev. 2012; 41:2780-2799. [PubMed: 22086677]

9. Chithrani BD, Ghazani AA, Chan WCW. Determining the Size and Shape Dependence of Gold Nanoparticle Uptake Into Mammalian Cells. Nano Lett. 2006; 6:662-668. [PubMed: 16608261]

10. Nativo P, Prior IA, Brust M. Uptake and Intracellular Fate of Surface-Modified Gold Nanoparticles. ACS Nano. 2008; 2:1639-1644. [PubMed: 19206367]

11. Arvizo RR, Miranda OR, Thompson MA, Pabelick CM, Bhattacharya R, Robertson JD, Rotello VM, Prakash YS, Mukherjee P. Effect of Nanoparticle Surface Charge at the Plasma Membrane and Beyond. Nano Lett. 2010; 10:2543-2548. [PubMed: 20533851]

12. Grabinski C, Schaeublin N, Wijaya A, D'Couto H, Baxamusa SH, Hamad-Schifferli K, Hussain SM. Effect of Gold Nanorod Surface Chemistry on Cellular Response. ACS Nano. 2011; 5:28702879. [PubMed: 21405102]

13. Paciotti GF, Myer L, Weinreich D, Goia D, Pavel N, McLaughlin RE, Tamarkin L. Colloidal Gold: A Novel Nanoparticle Vector for Tumor Directed Drug Delivery. Drug Delivery. 2004; 11:169_ 183. [PubMed: 15204636]

14. Song W-J, Du J-Z, Sun T-M, Zhang P-Z, Wang J. Gold Nanoparticles Capped with Polyethyleneimine for Enhanced siRNA Delivery. Small. 2010; 6:239-246. [PubMed: 19924738]

15. Clemens DL, Lee B-Y, Xue M, Thomas CR, Meng H, Ferris D, Nel AE, Zink JI, Horwitz MA. Targeted Intracellular Delivery of Antituberculosis Drugs to Mycobacterium tuberculosis- Infected Macrophages via Functionalized Mesoporous Silica Nanoparticles. Antimicrob. Agents Chemother. 2012; 56:2535-2545. [PubMed: 22354311] 
16. Sun T, Zhang YS, Pang B, Hyun DC, Yang M, Xia Y. Engineered Nanoparticles for Drug Delivery in Cancer Therapy. Angew. Chem., Int. Ed. 2014; 53:12320-12364.

17. Vroman L, Adams A, Fischer G, Munoz P. Interaction of High Molecular Weight Kininogen, Factor XII, and Fibrinogen in Plasma at Interfaces. Blood. 1980; 55:156-159. [PubMed: 7350935]

18. Green RJ, Davies MC, Roberts CJ, Tendler SJB. Competitive Protein Adsorption as Observed by Surface Plasmon Resonance. Biomaterials. 1999; 20:385-391. [PubMed: 10048412]

19. Choi S, Yang Y, Chae J. Surface Plasmon Resonance Protein Sensor Using Vroman Effect. Biosens. Bioelectron. 2008; 24:893-899.

20. Cedervall T, Lynch I, Foy M, Berggård T, Donnelly SC, Cagney G, Linse S, Dawson KA. Detailed Identification of Plasma Proteins Adsorbed on Copolymer Nanoparticles. Angew. Chem., Int. Ed. 2007; 46:5754-5756.

21. Monopoli MP, Walczyk D, Campbell A, Elia G, Lynch I, Baldelli Bombelli F, Dawson KA. Physical-Chemical Aspects of Protein Corona: Relevance to in Vitro and in Vivo Biological Impacts of Nanoparticles. J. Am. Chem. Soc. 2011; 133:2525-2534. [PubMed: 21288025]

22. Xia X-R, Monteiro-Riviere NA, Riviere JE. An Index for Characterization of Nanomaterials in Biological Systems. Nat. Nanotechnol. 2010; 5:671-675. [PubMed: 20711178]

23. Lundqvist M, Stigler J, Elia G, Lynch I, Cedervall T, Dawson KA. Nanoparticle Size and Surface Properties Determine the Protein Corona with Possible Implications for Biological Impacts. Proc. Natl. Acad. Sci. U. S. A. 2008; 105:14265-14270. [PubMed: 18809927]

24. Boulos SP, Davis TA, Yang JA, Lohse SE, Alkilany AM, Holland LA, Murphy CJ. NanoparticleProtein Interactions: A Thermodynamic and Kinetic Study of the Adsorption of Bovine Serum Albumin to Gold Nanoparticle Surfaces. Langmuir. 2013; 29:14984-14996. [PubMed: 24215427]

25. Lin W, Insley T, Tuttle MD, Zhu L, Berthold DA, Král P, Rienstra CM, Murphy CJ. Control of Protein Orientation on Gold Nanoparticles. J. Phys. Chem. C. 2015; 119:21035-21043.

26. Prescott DM, Charles HC, Poulson JM, Page RL, Thrall DE, Vujaskovic Z, Dewhirst MW. The Relationship between Intracellular and Extracellular $\mathrm{pH}$ in Spontaneous Canine Tumors. Clin. Cancer. Res. 2000; 6:2501-2505. [PubMed: 10873105]

27. Freeman RG, Hommer MB, Grabar KC, Jackson MA, Natan MJ. Ag-Clad Au Nanoparticles: Novel Aggregation, Optical, and Surface-Enhanced Raman Scattering Properties. J. Phys. Chem. 1996; 100:718.

28. Link S, El-Sayed MA. Size and Temperature Dependence of the Plasmon Absorption of Colloidal Gold Nanoparticles. J. Phys. Chem. B. 1999; 103:4212.

29. Jain PK, Lee KS, El-Sayed IH, El-Sayed MA. Calculated Absorption and Scattering Properties of Gold Nanoparticles of Different Size, Shape, and Composition: Applications in Biological Imaging and Biomedicine. J. Phys. Chem. B. 2006; 110:7238. [PubMed: 16599493]

30. Wang A, Vangala K, Vo T, Zhang D, Fitzkee NC. A Three-Step Model for Protein-Gold Nanoparticle Adsorption. J. Phys. Chem. C. 2014; 118:8134-8142.

31. Boersema PJ, Raijmakers R, Lemeer S, Mohammed S, Heck AJR. Multiplex Peptide Stable Isotope Dimethyl Labeling for Quantitative Proteomics. Nat. Protoc. 2009; 4:484-494. [PubMed: 19300442]

32. Freeman R, Mareci T, Morris G. Weak Satellite Signals in High-Resoluton NMR Spectra: Separating the Wheat from the Chaff. J. Magn. Reson. 1981; 42:341-345.

33. Piotto M, Saudek V, Sklenář V. Gradient-Tailored Excitation for Single-Quantum NMR Spectroscopy of Aqueous Solutions. J. Biomol. NMR. 1992; 2:661-665. [PubMed: 1490109]

34. Sklenar V, Piotto M, Leppik R, Saudek V. Gradient-Tailored Water Suppression for ${ }^{1} \mathrm{H}_{-}{ }^{15} \mathrm{~N}$ HSQC Experiments Optimized to Retain Full Sensitivity. J. Magn. Reson., Ser. A. 1993; 102:241-245.

35. Ivanov MR, Bednar HR, Haes AJ. Investigations of the Mechanism of Gold Nanoparticle Stability and Surface Functionalization in Capillary Electrophoresis. ACS Nano. 2009; 3:386-394. [PubMed: 19236076]

36. Goto Y, Calciano LJ, Fink AL. Acid-induced Folding of Proteins. Proc. Natl. Acad. Sci. U. S. A. 1990; 87:573-577. [PubMed: 2153957]

37. Wang A, Vo T, Le V, Fitzkee NC. Using Hydrogen-Deuterium Exchange to Monitor Protein Structure in the Presence of Gold Nanoparticles. J. Phys. Chem. B. 2014; 118:14148-14156. [PubMed: 25265213] 
38. Roberson KJ, Macnaughtan MA. Review of Methods to Assign the Nuclear Magnetic Resonance Peaks of Reductively Methylated Proteins. Anal. Biochem. 2014; 466:76-82. [PubMed: 25175010]

39. Waldron TT, Schrift GL, Murphy KP. The Salt-dependence of a Protein-Ligand Interaction: IonProtein Binding Energetics. J. Mol. Biol. 2005; 346:895-905. [PubMed: 15713470]

40. Kloss E, Barrick D. Thermodynamics, Kinetics, and Salt Dependence of Folding of YopM, a Large Leucine-rich Repeat Protein. J. Mol. Biol. 2008; 383:1195-1209. [PubMed: 18793647]

41. Han X, Goebl J, Lu Z, Yin Y. Role of Salt in the Spontaneous Assembly of Charged Gold Nanoparticles in Ethanol. Langmuir. 2011; 27:5282-5289. [PubMed: 21466161]

42. Baker NA, Sept D, Joseph S, Holst MJ, McCammon JA. Electrostatics of Nanosystems: Application to Microtubules and the Ribosome. Proc. Natl. Acad. Sci. U. S. A. 2001; 98:1003710041. [PubMed: 11517324]

43. Brahmkhatri VP, Chandra K, Dubey A, Atreya HS. An Ultrastable Conjugate of Silver Nanoparticles and Protein Formed Through Weak Interactions. Nanoscale. 2015; 7:12921-12931. [PubMed: 26166696]

44. Zanzoni S, Ceccon A, Assfalg M, Singh RK, Fushman D, D’Onofrio M. Polyhydroxylated [60]fullerene Binds Specifically to Functional Recognition Sites on a Monomeric and a Dimeric Ubiquitin. Nanoscale. 2015; 7:7197-7205. [PubMed: 25811293]

45. Zanzoni S, Pedroni M, D’Onofrio M, Speghini A, Assfalg M. Paramagnetic Nanoparticles Leave Their Mark on Nuclear Spins of Transiently Adsorbed Proteins. J. Am. Chem. Soc. 2016; 138:7275. [PubMed: 26683352]

46. Ceccon A, Tugarinov V, Bax A, Clore GM. Global Dynamics and Exchange Kinetics of a Protein on the Surface of Nanoparticles Revealed by Relaxation-Based Solution NMR Spectroscopy. J. Am. Chem. Soc. 2016; 138:5789-5792. [PubMed: 27111298]

47. Ulmer TS, Ramirez BE, Delaglio F, Bax A. Evaluation of Backbone Proton Positions and Dynamics in a Small Protein by Liquid Crystal NMR Spectroscopy. J. Am. Chem. Soc. 2003; 125:9179-9191. [PubMed: 15369375]

48. Vijay-Kumar S, Bugg CE, Cook WJ. Structure of Ubiquitin Refined at 1.8 Å Resolution. J. Mol. Biol. 1987; 194:531-544. [PubMed: 3041007]

49. Asuri P, Bale SS, Pangule RC, Shah DA, Kane RS, Dordick JS. Structure, Function, and Stability of Enzymes Covalently Attached to Single-Walled Carbon Nanotubes. Langmuir. 2007; 23:1231812321. [PubMed: 17944500]

50. De Roe C, Courtoy PJ, Baudhuin P. A Model of Protein-Colloidal Gold Interactions. J. Histochem. Cytochem. 1987; 35:1191-1198. [PubMed: 3655323]

51. Brewer SH, Glomm WR, Johnson MC, Knag MK, Franzen S. Probing BSA Binding to CitrateCoated Gold Nanoparticles and Surfaces. Langmuir. 2005; 21:9303-9307. [PubMed: 16171365]

52. Ameer FS, Ansar SM, Hu W, Zou S, Zhang D. Inner Filter Effect on Surface Enhanced Raman Spectroscopic Measurement. Anal. Chem. 2012; 84:8437. [PubMed: 23025423]

53. Siriwardana K, LaCour A, Zhang D. Critical Sequence Dependence in Multicomponent Ligand Binding to Gold Nanoparticles. J. Phys. Chem. C. 2016; 120:6900-6905.

54. Tenzer S, Docter D, Rosfa S, Wlodarski A, Kuharev J, Rekik A, Knauer SK, Bantz C, Nawroth T, Bier C, et al. Nanoparticle Size Is a Critical Physicochemical Determinant of the Human Blood Plasma Corona: A Comprehensive Quantitative Proteomic Analysis. ACS Nano. 2011; 5:71557167. [PubMed: 21866933]

55. Ju S, Yeo W-S. Quantification of Proteins on Gold Nanoparticles by Combining MALDI-TOF MS and Proteolysis. Nanotechnology. 2012; 23:135701. [PubMed: 22417878]

56. Anderson NL, Anderson NG. The Human Plasma Proteome: History, Character, and Diagnostic Prospects. Mol. Cell. Proteomics. 2002; 1:845-867. [PubMed: 12488461]

57. Duncan R, Gaspar R. Nanomedicine(s) Under the Microscope. Mol. Pharmaceutics. 2011; 8:21012141.

58. Tavanti F, Pedone A, Menziani MC. Competitive Binding of Proteins to Gold Nanoparticles Disclosed by Molecular Dynamics Simulations. J. Phys. Chem. C. 2015; 119:22172-22180. 
59. Engel MFM, Visser AJWG, van Mierlo CPM. Conformation and Orientation of a Protein Folding Intermediate Trapped by Adsorption. Proc. Natl. Acad. Sci. U. S. A. 2004; 101:11316-11321. [PubMed: 15263072]

60. Engel MFM, Visser AJWG, van Mierlo CPM. Adsorption of Bovine a-Lactalbumin on Suspended Solid Nanospheres and Its Subsequent Displacement Studied by NMR Spectroscopy. Langmuir. 2004; 20:5530-5538. [PubMed: 15986696]

61. Lundqvist M, Sethson I, Jonsson B-H. High-Resolution 2D ${ }^{1} \mathrm{H}-{ }^{15} \mathrm{~N}$ NMR Characterization of Persistent Structural Alterations of Proteins Induced by Interactions with Silica Nanoparticles. Langmuir. 2005; 21:5974-5979. [PubMed: 15952849]

62. Calzolai L, Franchini F, Gilliland D, Rossi F. Protein-Nanoparticle Interaction: Identification of the Ubiquitin-Gold Nanoparticle Interaction Site. Nano Lett. 2010; 10:3101-3105. [PubMed: 20698623]

63. Shrivastava S, McCallum SA, Nuffer JH, Qian X, Siegel RW, Dordick JS. Identifying Specific Protein Residues That Guide Surface Interactions and Orientation on Silica Nanoparticles. Langmuir. 2013; 29:10841-10849. [PubMed: 23906189]

64. Mondal S, Thirupathi R, Rao LP, Atreya HS. Unraveling the Dynamic Nature of Protein-Graphene Oxide Interactions. RSC Adv. 2016; 6:52539-52548. 

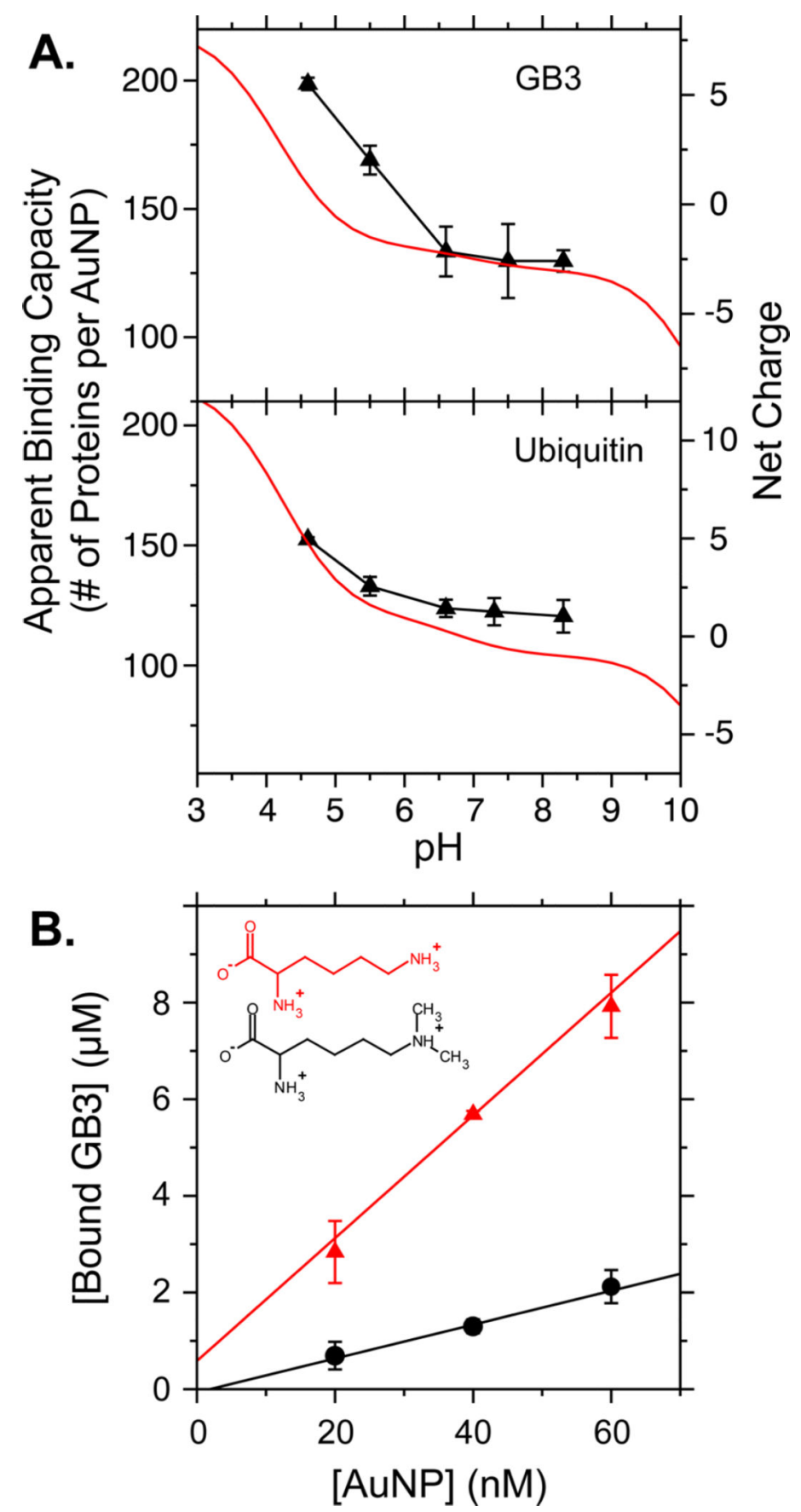

Figure 1.

Evidence for electrostatically driven binding. (A) Apparent binding capacities for GB3 (upper panel) and ubiquitin (lower panel) as measured using ${ }^{1} \mathrm{H}$ NMR spectroscopy. ${ }^{37}$ Binding is strongly dependent on $\mathrm{pH}$. The red curve (right axis) represents the net charge calculated using model-compound $\mathrm{p} K_{\mathrm{a}}$ values. (B) Apparent binding capacities of unmodified GB3 (red triangles) and GB3 with methylated lysine residues (black circles) at $\mathrm{pH}$ 7. Binding was measured at multiple AuNP concentrations, and the slope of the best-fit line measures binding capacity. The inset shows lysine (red) and methylated lysine (black). 
Error bars in this and all other figures represent the standard deviations from at least three independently prepared samples. 

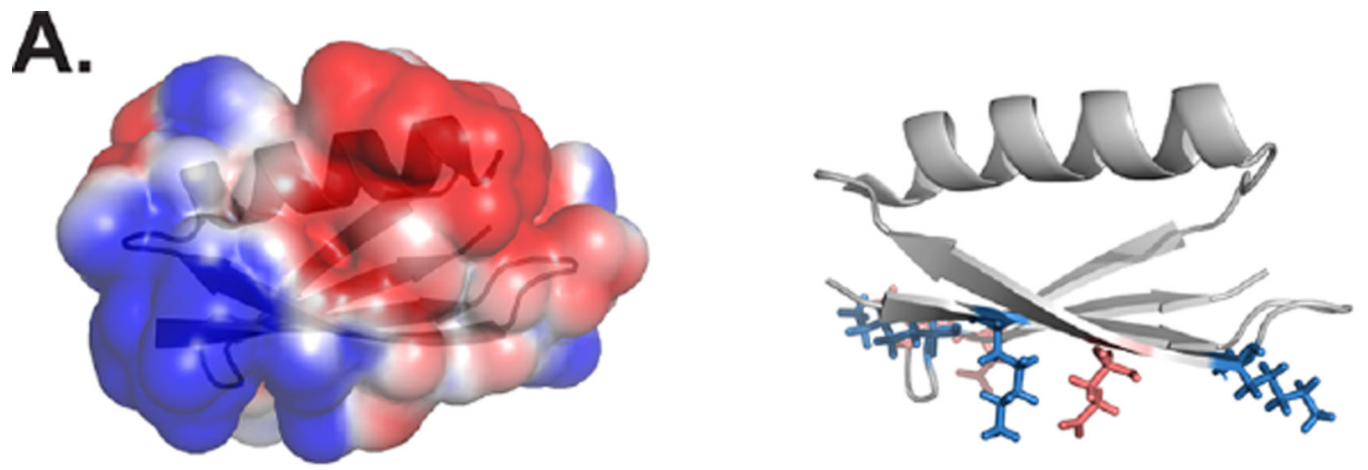

B.
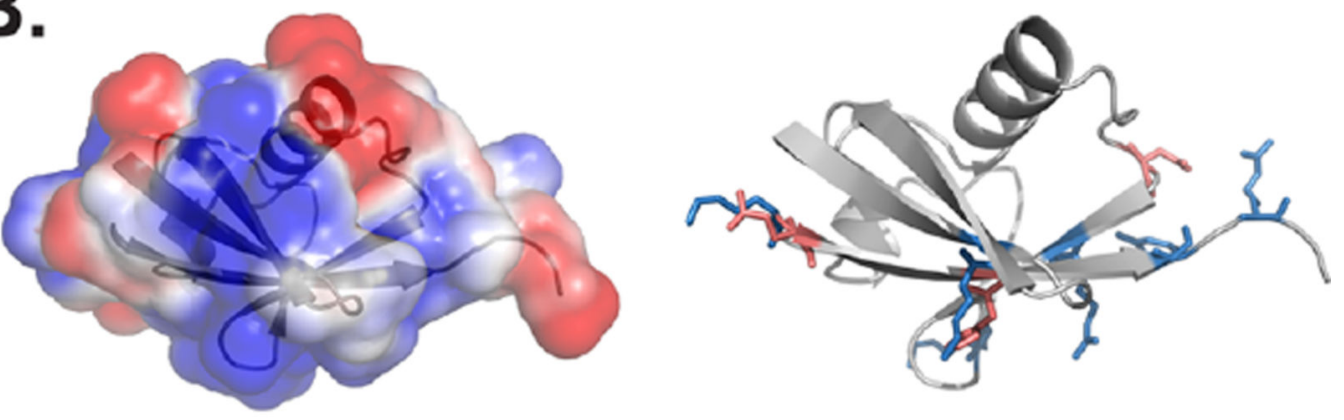

C.
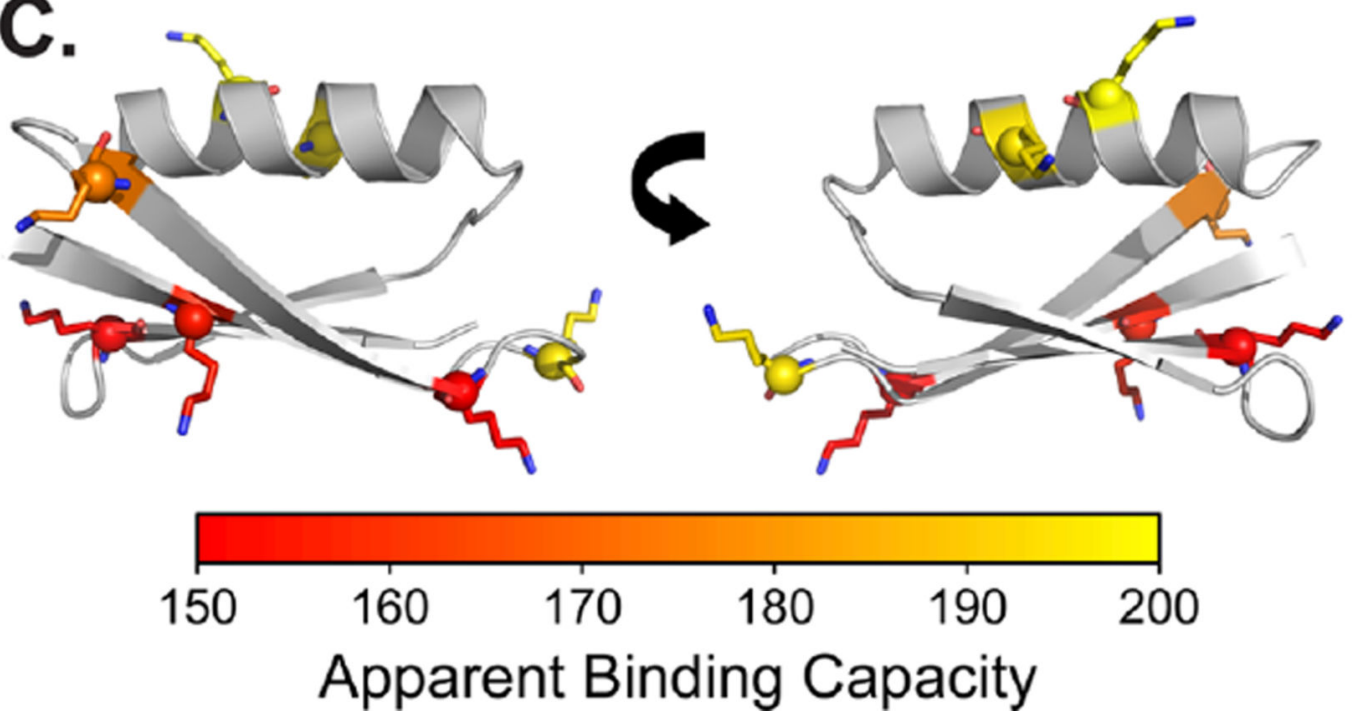

Figure 2.

Proposed binding sites for (A) GB3 and (B) ubiquitin binding to citrate-coated AuNP surfaces. (Left) Electrostatic surface of each protein as calculated by APBS. ${ }^{42}$ (Right) Illustration of ionizable residues proposed to be involved in binding. Specific residues are identified in the text. The proteins are oriented so that the nanoparticle-binding side faces down. (C) Lysine residues in GB3, shaded by the apparent number of GB3 molecules bound when each lysine is changed to alanine (using 15-nm AuNPs at pH 6.4). Yellow indicates near-maximal binding for the Ala mutant (200 per 15-nm AuNP), whereas red indicates 
diminished binding. Residues in red map closely to the proposed AuNP-binding site. The PDB entries used for GB3 and ubiquitin are $2 \mathrm{OED}^{47}$ and $1 \mathrm{UBQ},{ }^{48}$ respectively. 

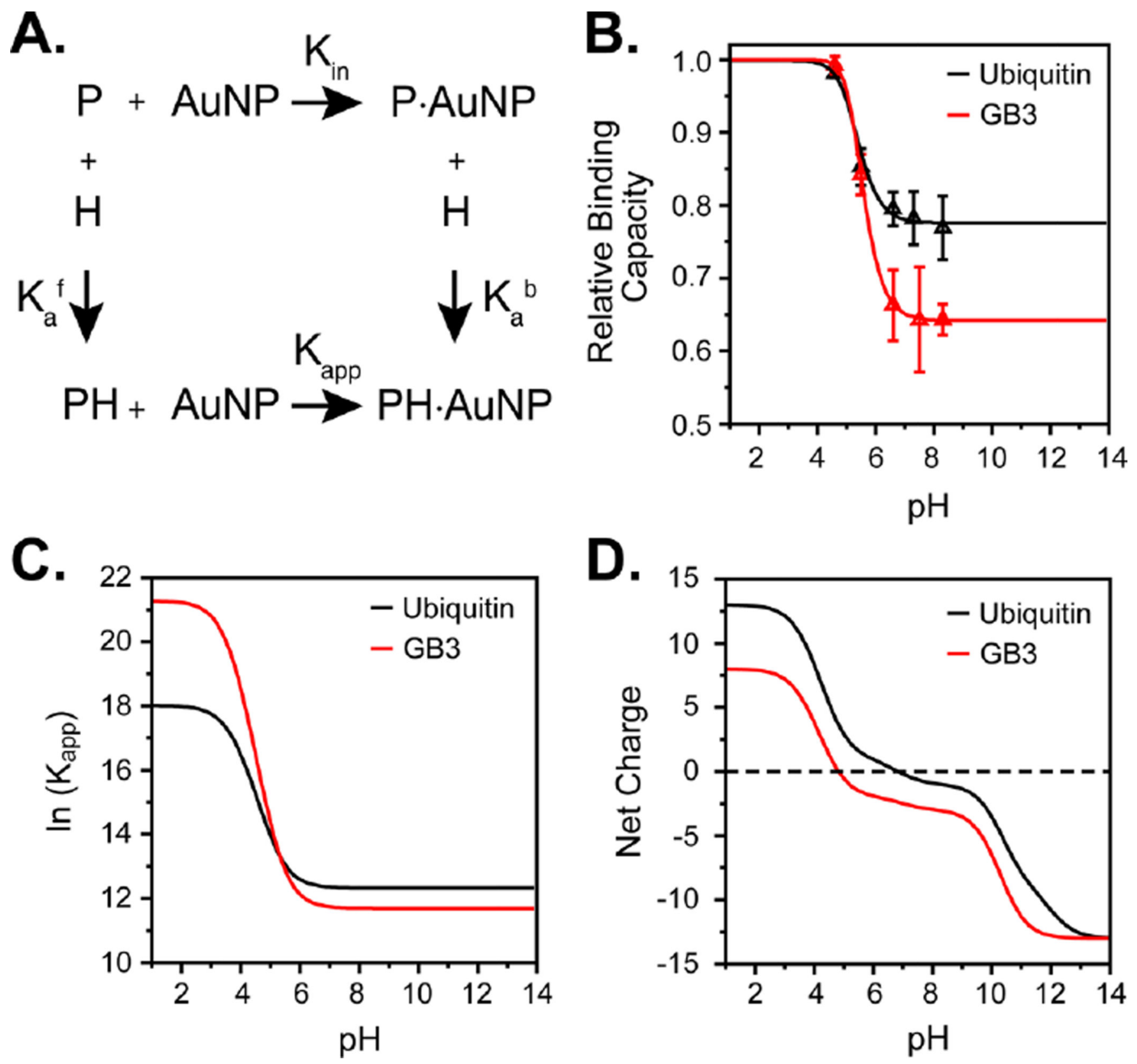

Figure 3.

pH-dependent model for protein-AuNP binding. (A) Thermodynamic cycle demonstrating binding for a single site. $K_{\mathrm{in}}$ and $K_{\mathrm{app}}$ are the intrinsic and apparent association constants, respectively, relative to the reference state described in the text; $K_{\mathrm{a}}^{\mathrm{f}}$ and $K_{\mathrm{a}}^{\mathrm{b}}$ are the acid dissociation constants of protein in the free and bound states, respectively. The model used in the text uses multiple binding sites (described in the SI). (B) Measured pH-dependent binding capacities of GB3 (red) and ubiquitin (black) after model fitting. Triangles represent the average observed binding for three independent measurements, and solid lines represent the fitted model. (C) Apparent binding affinity (ln $K_{\text {app }}$ ) vs pH for GB3 and ubiquitin, 
demonstrating an increase for GB3 at low $\mathrm{pH}$. (D) Net charge per protein $(Z)$ of the GB3 and ubiquitin molecules as a function of $\mathrm{pH}$ using model-compound $\mathrm{p} K_{\mathrm{a}}$ values. 

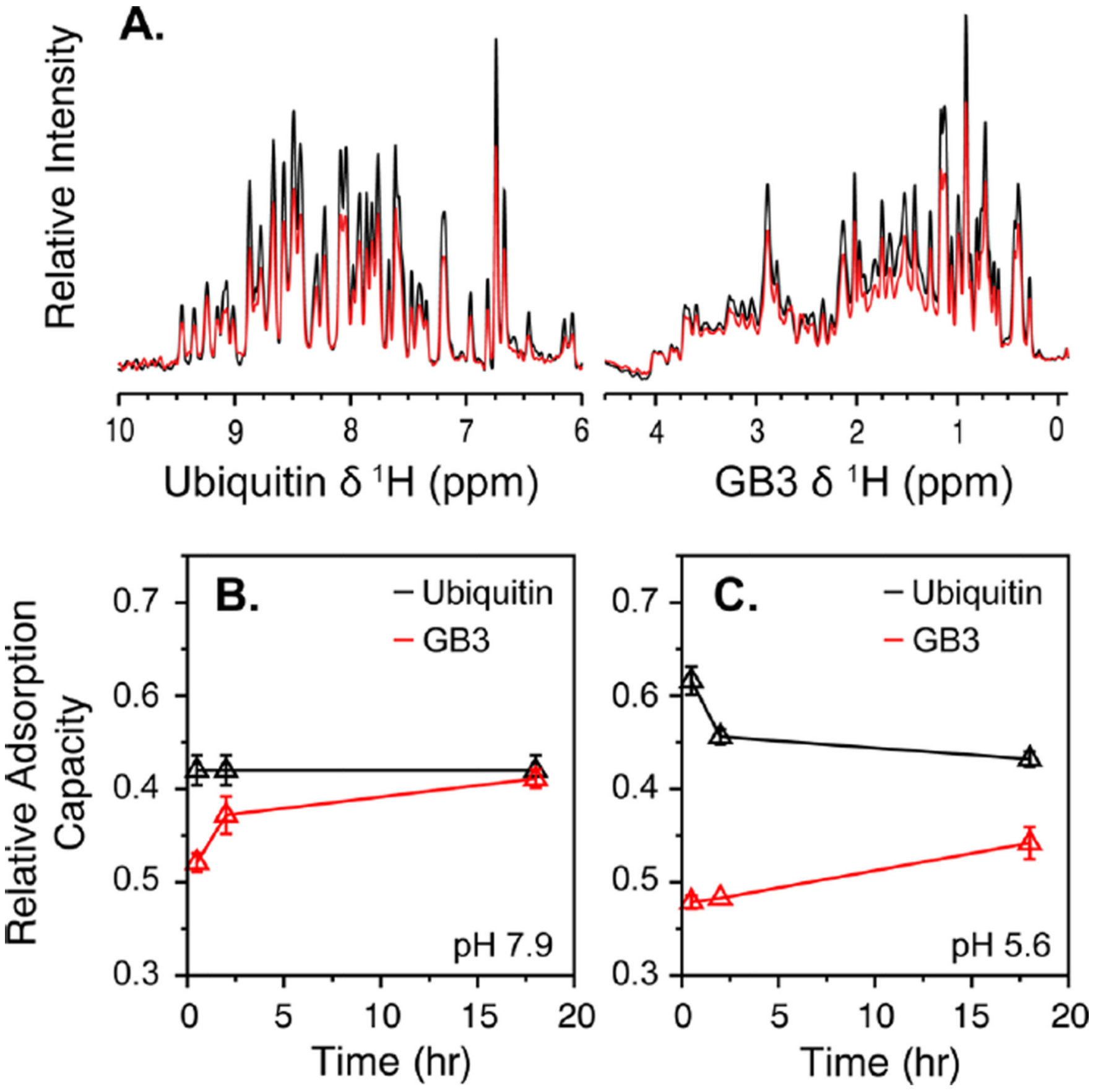

Figure 4.

Binding competition between GB3 and ubiquitin. (A) (Left) Amide proton NMR spectra of ${ }^{15} \mathrm{~N}$-labeled ubiquitin and (right) aliphatic proton spectra of ${ }^{13} \mathrm{C}$-labeled GB3 in the absence (black) and presence (red) of AuNPs. Each spectrum was obtained from a sample containing a mixture of the two proteins. A quantifiable decrease in signal for each protein was observed upon AuNP binding. (B,C) Kinetic profiles of binding competition between ubiquitin (black) and GB3 (red) at pH (B) 7.9 and (C) 5.6. The amount of bound protein, 
relative to the maximum for each protein in the absence of competition, was measured 0.5 , 2, and $18 \mathrm{~h}$ after addition of AuNPs. 
A.
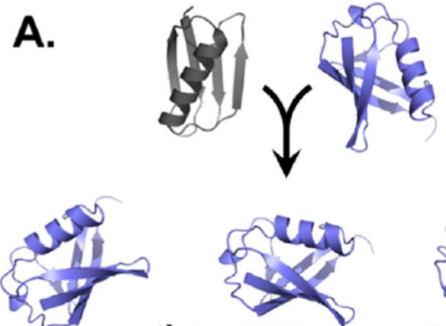

0.70 o $0 y^{0}$
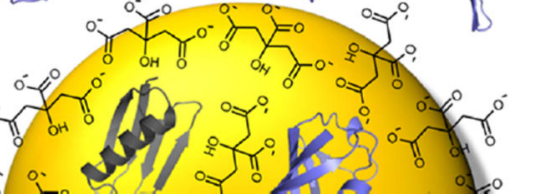

B.

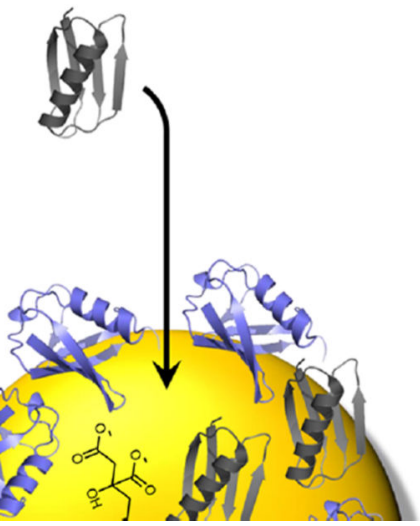

C.

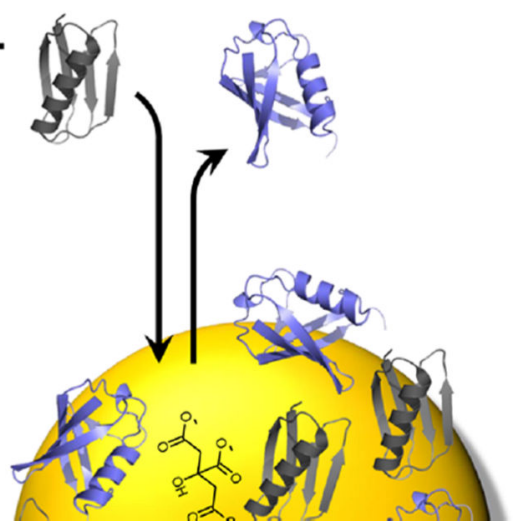

Figure 5.

Competition between GB3 (gray) and ubiquitin (blue) for AuNP surfaces under differing conditions. (A) At early stages of adsorption, the nanoparticle surface is coated with citrate, and ubiquitin, with a higher net charge, is drawn to the AuNP. (B) At high $\mathrm{pH}$, ubiquitin dominates, and GB3 cannot displace it from the surface. (C) At low pH, the increased positive charge allows GB3 to displace ubiquitin as it binds. Citrate molecules are not drawn to scale and instead represent regions of negatively charged surface. 


\section{Table 1}

Model Parameters for pH-Dependent Protein-AuNP Binding

\begin{tabular}{|c|c|c|c|c|}
\hline \multicolumn{5}{|c|}{ GB3 Model Parameters ${ }^{a}$} \\
\hline \multicolumn{5}{|c|}{$\mathrm{p} K_{\mathrm{a}}^{\mathrm{f}} \quad \mathrm{p} K_{\mathrm{a}}^{\mathrm{b}}$} \\
\hline Asp & 3.6 & $5.22 \pm 0.09$ & 1.6 & 2 \\
\hline Glu & 4.3 & $5.22 \pm 0.09$ & 0.9 & 1 \\
\hline Lys & 10.5 & 10.5 & 0.0 & 3 \\
\hline \multicolumn{5}{|c|}{ reference state: $K_{\text {in }}=(1.2 \pm 0.1) \times 10^{5}$} \\
\hline \multicolumn{5}{|c|}{ Ubiquitin Model Parameters $b$} \\
\hline & $\mathrm{p} K_{\mathrm{a}}^{\mathrm{f}}$ & $\mathrm{p} K_{\mathrm{a}}^{\mathrm{b}}$ & $\Delta \mathrm{p} K_{\mathrm{a}}$ & $N$ \\
\hline Asp & 3.6 & $5.18 \pm 0.07$ & 1.6 & 1 \\
\hline Glu & 4.3 & $5.18 \pm 0.07$ & 0.9 & 1 \\
\hline Lys & 10.5 & 10.5 & 0.0 & 3 \\
\hline $\operatorname{Arg}$ & 12.5 & 12.5 & 0.0 & 3 \\
\hline \multicolumn{5}{|c|}{ reference state: $K_{\text {in }}=(2.3 \pm 0.2) \times 10^{5}$} \\
\hline
\end{tabular}

